Est Ag 46 (2011) 327-339

\title{
Catalina de Siena, una laica mística en política
}

PABLo LóPez LóPEZ

RESUMEN: Catalina representa un puente entre tradición e innovación y, sobre todo, la hondura del autoconocimiento y la sabiduría de los humildes. Descuella siendo síntesis de mística y compromiso político como joven mujer laica, dentro de un tiempo de enorme crisis. Por eso, necesitamos catalinizarnos para cristificar nuestra alma y nuestra acción pública. La vida de Catalina marca un itinerario que acoge el Evangelio como laica para después ascender a la mística y, desde tal monte Tabor de unión con el Amado, desciende, se encarna a fin de dar la vida por la Iglesia y la humanidad. Vive con el corazón en el Cielo y los pies en la tierra. La eterna juventud de Catalina nos muestra con vigor la plenitud vital del cristiano.

PALABRAS CLAVE: laicidad, mística, política, humanismo, juventud, autoconocimiento, sabiduría.

ABSTRACT: Catherine of Sienna represents a bridge between tradition and innovation, and, above all, the depth of the self-knowledge and the wisdom of the humble people. In life, she excels for the synthesis between mystic and political commitment, has been a young secular woman, in a time of enormous crisis. Therefore, we need transform ourselves to Catherine of Sienna, in order to turn ourselves and our public actions alike those of Christ. The life of Catherine marks an itinerary that receives the Gospel as a lay person, in order later to elevate oneself to mysticism and, after being united with the beloved, to descend from the mount Tabor, to give up the life for the Church and the humanity. Setting her heart in the Sky, she lives with her feet firm on the ground. The eternal youth of Catherine show us the vigorous vitality of lived Christian fullness.

\footnotetext{
*e-mail: pablosanta@hotmail.com
} 
KEYWORD: laity, mysticism, politics, humanism, youth, self-knowledge, wisdom.

\section{Saludo inicial a la joven Catalina}

Con ocasión del XI Congreso de Católicos en la Vida Pública, en torno al tema de "la política, al servicio del bien común", vi oportuno proponer la figura de la joven santa de Siena precisamente en su vertiente activa pública y política. La ejemplaridad de un santo nunca caduca. $Y$ especialmente actual es el modelo de esta muchacha tan santificada en una infrecuente pero necesaria síntesis modélica de gran espiritualidad y esforzado compromiso político. Catalina es a la vez gigante en mística y en política. Catalina armoniza con sabiduría toda su vertiente externa, pública y política, y su vida recogida, espiritual y mística. Tal actualidad se acrecienta por las similitudes entre la severa crisis global que azotó el siglo XIV y la de nuestro tránsito de centuria y milenio.

Por un cúmulo de circunstancias adversas, no me es posible ahora poner a disposición todo el texto bien desarrollado sobre el que basé mi breve exposición durante el Congreso. No obstante, se me ha pedido que al menos presente una sucinta idea de mi propuesta. Con gusto lo hago, pese a las dificultades varias que me envuelven. Tras hablar en el Congreso, varios asistentes me mostraron tanto su naciente entusiasmo por Catalina, como su desconocimiento previo sobre la hondura de esta gran santa, de vida tan intensa y fructífera. Todo ello me espolea a presentar estas líneas, simples notas de lo que recuerdo haber querido decir durante el Congreso, hace meses. Sirvan de invitación a leer e imitar a Catalina. Hacerlo nos garantiza una estrecha imitación de Cristo como cristianos laicos en nuestra vida pública y política. Por ello estimo que también debería atraer la mirada de los hermanos ortodoxos y protestantes. Y por sus virtudes humanas, su ímpetu juvenil y su particular valía femenina, Catalina tiene mucho que decir a cualquier humanista, a los jóvenes inquietos y al feminismo bien entendido.

Sin más, demos un inicial saludo a nuestra precoz heroína. Al presentar los rasgos básicos de su vida, personalidad y obra, nada habrá que exaltar. Son elocuentemente brillantes por sí mismos y sólo espero acertar a expresarlos con un mínimo de transparencia. Ella vivió de modo extraordinario su cotidianidad. Vivió con excepcional grandeza su evidente pequeñez. Muy pocos han llegado tan lejos con tan pocos medios humanos. Recibió gracias especiales, pero también topó con continuas y descomunales dificultades que superó con heroico coraje y prudencia exquisita. En los pequeños como Catalina brillan más la presencia y la acción de Dios. Fue una vigorosa llama 
de amor humano-divino desde su inicial vida apartada doméstica hasta su intrépida época final de viajes e intervenciones pacificadoras en las más altas instancias políticas y eclesiales.

Pese a reunir su santidad una inusual cantidad de los más altos reconocimientos (copatrona de Roma, Italia y Europa, copatrona de enfermería y la más antigua doctora de la Iglesia), incluso la gran mayoría de los católicos fervorosos no suele pasar de una idea vaga sobre Catalina. Procede que indiquemos o recordemos lo más elemental.

Caterina Benincasa (así reza su nombre y su apellido italianos) es una joven de la segunda mitad del siglo XIV.Vive entre finales de la Época Gótica (del mal llamado "Medievo") y el inicio de la Modernidad renacentista, que justamente estaba surgiendo por adelantado en su tierra toscana. Su propia prosa es un destacado ejemplar de la nueva cultura y de la nueva literatura que brotaban entonces. Catalina es la primera literata italiana conocida. El corazón de Catalina recoge esencias concentradas de la flamígera espiritualidad del siglo precedente, sobre todo de línea dominica. A la vez, en perfecta síntesis, su estilo personalísimo y el contexto de renovación avanzada de ese fin de siglo XIV en el centro de Italia, la llevan a ser pionera, abriendo una veta magistral perenne. Catalina es sintesis y puente entre épocas, y entre la Tradición apostólico-eclesial y el impulso vanguardista y rejuvenecedor del Espíritu. Ella reúne la luz transcendente del Gótico y los aires intensos de reforma, reconciliación y libertad, que son el énfasis distintivo con que se abre la Modernidad. Su reformismo es auténtico, es el de los santos, fiel al Evangelio y a la Iglesia, sin rupturismos fragmentadores como los del siglo XVI.

Nace en 1347 como penúltima hija de veinticinco hermanos (aquí ya comienza lo asombroso) de una familia trabajadora de Siena. Con seis años experimenta una visión de Jesucristo pontífice junto a Pedro, Pablo y el evangelista Juan. Ya se siente llamada a una total entrega a Dios. A sus siete años consagra en privado su virginidad al Señor. Tal voto le cuesta un duradero castigo de su familia, que desde sus doce años ya la orienta hacia el matrimonio. Durante años ha de asumir todo tipo de trabajos y servicios domésticos humillantes, pero nunca se quiebran su ánimo y su voluntad. Sin posibilidad de contar por entonces con un lugar propio de retiro, cultiva esmeradamente su "celda interior" durante años de vida recogida, intensa oración y penitencia. No sin dificultad, a los dieciséis años es acogida entre unas terciarias dominicas conocidas como "manteladas". Continúa su apartada vida de oración y penitencia en su habitación familiar. Es eremita en medio de la urbe. 
Sólo a los veinte años aprende a leer y aún tardará más años en aprender la escritura. Con tal edad goza de una experiencia de mística unión matrimonial con Jesucristo e inicia la redacción de cartas y su amplia labor caritativa con pobres, enfermos y presos. Los veintitrés años vienen marcados por la vivencia del intercambio de corazones entre Catalina y Jesús. Considérese la importancia que siglos después cobrará la devoción al Corazón de Jesús. Ya con sólo veinticuatro años la iletrada Catalina se ve seguida por numerosos discípulos. Entre ellos habrá incluso eminentes teólogos. Sus consejos serán solicitados y acogidos por papas, reyes y muchas más personas insignes de variada procedencia. Catalina representa la sabiduría de los humildes, de los que se conocen a símismos y piensan por símismos sin respetos humanos ni lastres convencionales. Sobre todo muestra la sabiduría que mana de la oración sincera y de la entrega amorosa a Dios. Sin menoscabo de tal sabiduría aprendida en el trato directísimo con el Señor y en su propia meditación, Catalina es comunitaria y se deja guiar por los directores espirituales que la Orden le ofrece. Entre éstos destaca el beato Raimundo de Capua, que llegará a ser maestro general de los dominicos y su principal biógrafo. A los veintiocho años recibe los estigmas de la Pasión, aún de modo invisible.

Catalina es requerida por el papa y diversas repúblicas para mediar a favor de soluciones pacíficas a grandes conflictos inminentes. Convence a Gregorio XI de dejar Aviñón para regresar a Roma. Al explotar el llamado "Cisma de Occidente", apoya al cuestionado papa Urbano VI. Su ardiente apoyo al "dulce Cristo en la tierra", no le ahorra su sentido crítico hacia ciertos procedimientos imprudentes de este papa. Sufre con los enfrentamientos dentro de la Iglesia, por cuya reforma suspira y ruega. Principalmente ofrece su vida por la causa de la reconciliación y la unidad de la Iglesia. En Roma, un mes después de alcanzar la edad de Cristo, llega al encuentro definitivo con Dios.

Dictó un solo libro (a los veintinueve años), conocido como "Diálogo de la Divina Providencia". En efecto, se trata de un diálogo entre el alma meditativa y contemplativa de Catalina y el Padre eterno. Es una cumbre de la literatura espiritual. Sorprende por combinar una gran estima de la razón, hondura metafísica, penetración psicológica, expresividad viva en imágenes, médula bíblica y ternura mística. Reitera mucho sus ideas e imágenes principales, al tiempo que va introduciendo nuevos paisajes meditativos, teológicos y morales. Se han recogido trescientas ochenta y una cartas dirigidas a todo tipo de personas. Constituyen un prodigioso apostolado epistolar. $\mathrm{Su}$ obra escrita se completa con una serie de oraciones recogidas por sus discípulos, ecos de su continuo diálogo con el Señor. 


\section{Catalina laica}

Catalina es laica y seglar consagrada. No pertenece al clero ni es monja. Y el concepto de "consagración" es muy amplio, no excluyendo a los laicos, consagrados a Cristo desde el bautismo. Entre todos los doctores de la Iglesia Catalina es la única de tal condición laica y seglar. Es la gran doctora laica y secular.

Ser laica y mujer en su época, como en tantas otras, le restó oportunidades de formación. Súmense su muerte tan joven y su intensa dedicación a obras de piedad y caridad. De hecho, es el doctor o doctora de la Iglesia con menor formación académica. Ni atravesó el itinerario formativo y espiritual monástico. Por todo ello, es la que en su sabiduría debe más a su personal vida de oración y a su propio pensamiento original. Esto nos muestra dónde están las principales fuentes de sabiduría: la oración y el propio pensamiento; y cuáles son secundarias: la formación académica y la cultura convencional. Con frecuencia estas últimas se tornan en obstáculos para la sabiduría. Como nos escribió el apóstol Pablo, la sabiduría de Dios resulta necedad ante ojos humanos. Y el propio Jesús nos advierte que lo que Dios oculta a los sabios de este mundo, lo revela a los humildes y sencillos. Es una bienaventuranza que brilla en nuestra joven sienesa. Ni por años vividos ni por libros leídos pudo Catalina alcanzar su magistral sabiduría humana y divina, terrenal y celeste. Pero siempre vivió muy cerca del Maestro y supo aprender a fondo de cuantas experiencias su itinerario apostólico le brindó.

Su laicidad consagrada anticipa un tipo de vocación que ha proliferado tanto desde el siglo XX, y particularmente desde el Vaticano II, un concilio muy dinamizador del laicado. Hoy en día son innumerables los institutos y comunidades de vida cristiana que destacan por diferentes fórmulas de vida laical consagrada mediante ciertos votos o compromisos.

Con todo, la libertad y la originalidad grandes de esta santa la hacen especialmente inclasificable, como en realidad son inclasificables los caminos de Dios. En verdad, lo que hasta hace poco se ha llamado la "Tercera orden" de los dominicos, fue laica y seglar desde sus inicios con las fraternidades penitenciales y apostólicas de Santo Domingo de Guzmán. Con el tiempo, algunas de estas fraternidades de mujeres se acercaron a un estilo de vida comunitario y célibe que adelantaría rasgos de la vida conventual activa de siglos posteriores. Un ejemplo de ello es el de las manteladas a las que se adscribió Catalina. Con todo, la joven sienesa no dejó de ser laica y seglar, por más consagrada y célibe que fuese desde antes de su ingreso entre las terciarias dominicas. Una vía laical y seglar es precisamente el celibato consagrado. 
Por lo demás, su estilo de vida en los escenarios públicos y su gran libertad de iniciativa son propios del laicado y particularmente ejemplares para cualquier laico de cualquier tiempo. Su vocación de apostolado en plena escena política, de evangelización de las estructuras y los ambientes decisivos del mundo, es evidentemente laica y secular. Su mística se encarnó en cancillerías, a lo ancho y largo de gran parte de la Europa de su época. Hizo época.

Con todo, la vertiente mística y recoleta de Catalina también es muy relevante para las almas más contemplativas y la vida monacal. Ella misma fundó un monasterio en Siena y ha inspirado la vocación de muchas monjas de clausura y de vida activa que buscan su patronazgo en el nombre de sus conventos y congregaciones.

Y no menos puede inspirar Catalina al clero. Ella colaboró estrechamente con presbíteros de su entorno, como los frailes dominicos, sin olvidar a sucesivos obispos de Roma. Más profundamente, Catalina llevó una intensa vida sacerdotal, propia de todo bautizado, que realmente es sacerdote, profeta y rey. Su permanente espíritu de sacrificio amoroso, de penitencia reparadora, hizo de su vida una cruz de ofrenda sacerdotal de sí misma, inconfundible con el sacerdocio ministerial, pero complementaria y ejemplar para éste. El apasionado cristocentrismo de Catalina era staurocéntrico, cruciforme.

Catalina es muy consciente de la interdependencia de todos los estados de vida dentro de la Iglesia: "Así el clérigo y el religioso necesitan al seglar y el seglar al religioso" (Diálogo, cap. 148). El laicado no puede tomarse como mero auxiliar o refuerzo del clero o de los monasterios. Casi toda la Iglesia se compone de laicos seglares, y aun el clero y la vida cenobítica parten del sacramento laico por excelencia: el bautismo. Todos los cristianos son laicos o lo han sido muchos años.

\section{Catalina mística}

Éste es el aspecto más célebre de Catalina, conocida sobre todo como la gran mística que es. Sin embargo, por su propia índole intimísima y casi inefable, es la vertiente más difícil de glosar, pese a contar con los propios textos de la santa. En todo caso, ayuda situar a Catalina en su espléndido contexto de mística y santidad del siglo XIV. En él destaquemos a grandes figuras de su misma espiritualidad dominica, aunque de cultura germánica y tendencia muy especulativa y algo cabalística: el maestro Eckhart, Juan Taulero y el beato Enrique Suso; al beato flamenco Juan Rusbroquio, canónigo re- 
gular de San Agustín; al diácono holandés Gerardo Groot, iniciador de la "devotio moderna"; a otra gran dama de la mística y de la vida pública, santa Brígida de Suecia, junto a una de sus hijas también llamada Catalina; a la reina aragonesa Santa Isabel de Portugal, que, como nuestra Catalina, fue una gran pacificadora laica terciaria; al cartujo Ludolfo de Sajonia, autor de la primera e influyente "Vida de Cristo"; a la primera autora conocida de un libro en lengua inglesa, la anacoreta Juliana de Norwich, coincidente en algunas nociones con nuestra Catalina e influida por otro místico inglés del XIV, el canónigo agustiniano Walter Hilton; y, como Juliana, entre los siglos XIV y XV, a dos sublimes predicadores, al también dominico San Vicente Ferrer y, nacido el mismo año de la muerte de Catalina, a su paisano franciscano San Bernardino de Siena. En Inglaterra se dan posiciones que anticipan parte de lo que serán los movimientos protestantes del siglo XVI: el antipapismo visceral y el voluntarismo nominalista del franciscano Guillermo de Ockham; y en Juan Wickliffe el biblicismo excluyente, multiinterpretable y contrario a la autoridad y a la mediación eclesial. Éstos desarrollan un agustinismo muy parcial y contradictorio que choca con la figura global y la dostrina del obispo de Hipona. Entre tanto, el oriente bizantino centrado en Constantinopla desfallecía ante el cerco otomano y por sus propias disputas teológicas, como la que dividía a partidarios y detractores del hesicasmo (espiritualidad concentrada en la quietud, el silencio y una jaculatoria íntima dirigida a Jesús). A favor del hesicasmo descollaron San Gregorio Palamás, San Eutimio de Bulgaria, Nicolás Cabasilas y los monjes del monte Athos. Santos rusos del siglo XIV son, por ejemplo, la archiduquesa moscovita Santa Eudoxia Dimítrievna, el príncipe ruso San Dimitri Donskoi, el metropolita San Alejo de Moscú y el misionero San Esteban de Perm. De Serbia recordemos a San Lazar.

Si los santos contemporáneos perfilan un inmediato contexto espiritual, la santidad resplandece aún más en el testimonio de vida en Cristo que se lega a las futuras generaciones. La santidad de Catalina ha seguido inspirando a lo largo de los siglos hasta nuestros días. Destaquemos dos ejemplos preclaros. Entre los siglos XVI y XVII descuella el de la primera santa canonizada de América, la hispano-peruana y también terciaria dominica Santa Rosa de Lima. Una patrona laica de Europa inspira a una patrona laica de América y Filipinas. Las dos santas jóvenes son grandes místicas y ascetas, entregadísimas al Señor, a pobres y enfermos, iletradas, pero sapientísimas, y ambas intervienen heroicamente en la vida pública hasta lograr la paz. Y desde el siglo XX conviene resaltar la labor de la Asociación Internacional Cataliniana ("Cateriniana"), que acoge a laicos seglares, re- 
ligiosos y clérigos, a cristianos de toda confesión y a no cristianos atraídos por el ejemplo de la joven sienesa.

Catalina posee unas claras coordenadas espirituales. La corriente dominicana, en la que se inscribe, la sitúa en una órbita agustiniana. El propio Santo Domingo partió de la regla de San Agustín y, más concretamente, de la regla de los canónigos regulares de San Agustín, como la orden premostratense en la que también se inspiró el santo castellano para fundar la orden de predicadores (dominicos). En tal regla se combinaba vida comunitaria y contemplativa con la predicación y todo tipo de apostolado entre la gente. Mientras que las tradiciones monásticas benedictina y oriental son prioritaria o exclusivamente contemplativas, la agustiniana concierta contemplación y una amplia acción pastoral o de apostolado, tal como muestra la vida de Catalina. Admitido tan evidente marco espiritual en nuestra santa, hay que insistir en su conspicua originalidad. No es mujer de escuela ni depende de formalismos conceptuales. Frente a la tendencia muy especulativa y abstracta de los místicos germanos contemporáneos de su orden, ella brilla en la concreción plástica de sus imágenes (Cristo como puente, el énfasis en la sangre de Cristo, etc.), que bien plasman sus afectos y su teología. No deja de ser atrevida en sus expresiones y acentos, como lo puede ser también Juliana de Norwich, pero frente a ciertas propuestas ambiguas de Eckhart o de Juliana, Catalina combina atrevimiento, originalidad y pureza ortodoxa. Busca con ahínco la pureza de la Iglesia, pero no incurre en ningún puritanismo intransigente y rupturista, como el de Wickliffe y el de los husitas. Aboga, por ejemplo, por la reforma del clero, no por su drástica eliminación o su sustitución por un sucedáneo de laicos clericalizados.

Desde muy niña ésta fue la clave de Catalina: su completa unión amorosa con Dios en Jesucristo. Murió tan joven, que con naturalidad mantuvo la infancia espiritual que el Evangelio aconseja. A la vez, paradójicamente, su ternura y sencillez espiritual crecían en un vigor y una madurez extraordinariamente precoces. Dios obra pronto sus maravillas cuando no se le ponen obstáculos y se colabora con Él. Y pronto dotó a Catalina de gran dulzura y gran fortaleza. Esta niña tenía la fuerte personalidad de cien caudillos guerreros. Ni su familia, ni la difamación, ni las diversas incomprensiones eclesiales, ni obstáculo alguno doblegaron su férrea voluntad y su atinado criterio propio. Escribe y actúa con un estilo personal inconfundible. Aprende de las fuentes puras de la verdad y siempre es ella misma, sin concesiones al qué dirán. Incluso su fidelidad al papa no la apartó de criticar excesos o imprudencias. Así surge una verdadera mística, con los pies bien plantados en la tierra, en lo real. La mística cierta es lo más contrario a un 
escapismo espiritualista o a una ensoñación edulcorada e ingrávida. La mística es zambullirse en la más densa y originaria realidad: Dios.

La mística consiste en nuestra personal e íntima unión con Dios, como anticipo o prenda de la beatífica visión celeste. Por ello sintetiza bien la acendrada vida mística de Catalina esta fórmula que expresa su unión con Dios: "La unión de su alma con Dios era más perfecta que la unión entre el alma y el cuerpo" (Diálogo, capítulo 19). Esta mujer de ardoroso deseo de amor, de "santo fuego de amor", como dice tres líneas antes, afirma tal unión partiendo de que la unión cuerpo-alma es substancial, según la tradición aristotélico-tomista, presente en sus escritos. La unión entre el alma y Dios llega a ser, pues, substancialísima, máxima. Somos más para Dios que para nosotros mismos.

Ya en el primer capítulo de su obra central, el Diálogo, nos muestra el camino de la oración como el de la unión con Dios, hasta el punto de que Dios nos transforma en sí mismo: "La oración, ejercitando al alma, la une a Dios y la hace seguir las huellas de Cristo crucificado; así, Dios hace de ella otro símismo, por deseo, afecto y unión de amor." Socráticamente, insiste en el conocimiento de sí, sobre la base de la naturaleza racional con la que Dios nos ha creado. Ahora, tal conocimiento sólo se realiza conociendo en los propios adentros, agustinianamente, a Dios, a través del amor. Sobre todo (añade en el segundo capítulo), "en la Comunión el alma se abraza más dulcemente a Dios, conoce mejor su verdad, estando el alma en Dios y Dios en el alma."

Todas sus gracias místicas, su cabal entrega ascética y toda su portentosa obra caritativa y política no son más que manifestaciones de lo único importante: su amor incondicional e inconmensurable a Cristo y a su Cuerpo Místico, la Iglesia. Precisamente por este amor Catalina es tan santa, obra maestra de Dios. Por tal amor y el consiguiente buen uso de su libertad la admiramos. Y por esta misma santidad de Catalina felicitamos y damos gloria a Dios, que ha concedido tamaño regalo a la Iglesia y a la humanidad.

\section{Catalina política}

El contexto sociopolítico del siglo XIV europeo fue muy convulso y desfavorable: Guerra de los Cien Años, peste negra, hambruna, Cisma de Occidente, gran presión otomana y crisis del equilibrio racional escolástico. Se estaba diluyendo todo un modelo cultural y espiritual, y, entre luces y penumbras, se abría paso una nueva época. También nosotros hemos transitado de un siglo a otro, de un milenio a otro y, en una acelerada y honda mu- 
tación cultural sin precedentes, nos adentramos en una global crisis de valores morales y religiosos y de racionalidad profunda. En tal crisis, junto a grandes declaraciones y avances legislativos pro derechos humanos, presenciamos las mayores matanzas humanas de la historia. Ahora, si el siglo XX no ha alcanzado las cimas místicas de siglos como el XIV y el XVI, sí ha estado a la par en cuanto a la renovación espiritual de aquellos tiempos (nuevo movimiento ecuménico, Concilio Vaticano II, movimientos pentecostal y carismático, relanzamiento misionero, proliferación de congregaciones y movimientos, etc.). En todo caso, tanto el XIV como los últimos cien años son, en líneas generales, de crisis, desazón y desequilibrios múltiples y hondos en todo el mundo. Así las cosas, Catalina, gran renovadora y reformadora en tiempos de crisis, es de las figuras que en tiempos recios y agitados puede orientarnos mejor para vivir aportando soluciones y dando un buen servicio a personas, a pueblos enteros y a la Iglesia universal.

Como ya sabemos, la joven sienesa conoce años de intensísima vida interior, de oración, soledad y penitencia. En cierto modo recuerdan los años del Señor en su vida oculta de Nazaret y su prueba en el desierto. En paralelo a cómo Jesucristo pasó de su vida oculta a su vida pública de predicación, Catalina recibe una moción del Señor al apostolado en la vida pública, con vistas a la salvación de las almas. La fortaleció en este empeño una visión recibida sobre la situación de las almas en los estados de gloria, de purgatorio y de condenación. Saliendo al encuentro de las personas, realizará también el ideal dominico de la predicación. De hecho, Catalina es una de las mejores predicadoras que ha conocido la Iglesia. Esto nos da esperanza en la aparición de muchas y grandes predicadoras del Evangelio y de sus valores de justicia social. El testimonio de Catalina fue cauce de conversiones como la del padre provincial de los franciscanos de Siena, que abandonó toda su arrogancia teológica y sus apegos terrenos. Por lo demás, incluso el Platón de "Politeia" ("República") prescribía contemplar las verdades eternas y saborear las mieles del bien, la belleza y la justicia suprasensoriales antes de embarcarse como guía en los vaivenes terrenos de la política.

Catalina armoniza a la perfección su vida íntima y su compromiso exterior bajo la clave de la ciudadanía. Se refiere a la vida interior de su alma como la de "la ciudad propia", mientras que la vida pública y política es para ella "la ciudad prestada". Todo es ciudadanía, civismo, convivencia, tanto la ciudadanía más espiritual que nos dirige a la Ciudad Celeste, como la temporal por la que transitamos. Catalina, como Agustín, aspira a la Ciudad de Dios, que no es sino el Reino de Dios, ya incipientemente presente en la tierra. Como el propio Evangelio, nuestra joven posee una visión espiritual y transcendente de lo sociopolítico y una visión sociopolítica y encarnada de 
lo espiritual. Los ámbitos se distinguen bien, pero se evitan espiritualismos, materialismos y percepciones dualistas o desintegradas de la global vida humana.

La acción social y, en gran medida, pública de Catalina se inicia en su asistencia incansable y personalizada a pobres, enfermos y presidiarios, sobre todo en el caso de algún reo de muerte. Acude solícita a una gran epidemia de peste. No rehúye atender a enfermos incurables, ingratos y con dolencias extremamente repulsivas. Mientras tantos demagogos y aprendices de revolucionario hablan y hablan de los pobres sin acercarse a ellos o aprovechándose de ellos, Catalina vive pobre entre pobres, compartiendo y aliviando su miseria.

Su obra asistencial se completa con su variada labor diplomática y pacificadora dirigida a evitar guerras entre repúblicas o reinos (incluidos los Estados Pontificios) y disensiones entre cristianos. Semejante tarea de política internacional se nutre de su singular capacidad de consejera, que también ejerce con un amplísimo abanico de personas de toda condición social. $\mathrm{Su}$ conocimiento de sí, labrado en su conocimiento interno de Dios, le ayuda a conocer las diversas realidades sociales y personales. En cambio, la necedad de muchos hombres de nuestro tiempo es pretender ser sabios a espaldas de Dios.

Por un lado, podemos ilustrarnos con la propia actuación diplomática de la santa ante diversas autoridades en relación con asuntos de gran relieve internacional e histórico. En cierta forma, cabe asimilar esta tarea a un sano ejercicio de "lobby" o cabildeo actual, pero con una especial autoridad moral y espiritual. Por otro, es muy rica la serie de consejos concretos individualizados que dirige a las autoridades civiles y eclesiásticas. Sería interesante comparar la orientación para gobernantes que ofrece Catalina y la de otros tratadistas clásicos, análogos como Erasmo ("Educación del príncipe cristiano") u opuestos como Maquiavelo ("El príncipe").

La dimensión política de Catalina aún merece mejores y más amplios estudios, sobre todo en lengua española. En italiano cabe destacar un breve, pero enjundioso volumen que recoge textos de la santa, adecuadamente ordenados y comentados: "La città prestata (Consigli ai politici)", editado por Gianfranco Morra, Città Nuova, 1990, 168 pp. Vemos, por ejemplo, cómo Catalina advierte del gran peligro del amor propio, o propugna la virilidad y la valentía del gobernante, y la conjunción de moral y política. 


\section{Necesidad de catalinizarnos}

La tentación con estos santos tan elevados y originales es que nuestra admiración hacia ellos se torne en una disimulada distancia. Podemos sentir la cómoda excusa de que toda su vida es tan elogiable como inimitable. Vayamos por partes.

Nunca se trata de imitar literal y forzadamente. Dios tiene un trato personalizado con cada uno de nosotros y conoce nuestros ritmos y límites. En todo caso, el modelo central para el cristiano no es otro que Cristo. Precisamente por ello, son una gran ayuda los ejemplos de los santos a lo largo de la historia. Ilustran con claridad cómo seguir a Cristo en una creciente variedad de situaciones y cómo Dios actúa en cada uno de ellos. No se trata de hacer esto o aquello, pero jcuánto avanzaríamos humana y cristianamente, si amáramos a Cristo de modo tan siquiera parecido al de Catalina!

De la riquísima y variada personalidad cristiana de Catalina cada cual puede resaltar y tomar lo que más le convenga para suscitar o fortalecer su seguimiento de Cristo. En concreto, aquí hemos destacado su ejemplar síntesis de mística y compromiso político como joven mujer laica, dentro de un tiempo de enorme crisis como el suyo y como el nuestro. Al menos en cierta medida, es patente que necesitamos catalinizarnos para cristificar nuestra alma y nuestra acción pública y política.

Recapitulemos para que cunda tan buen ejemplo. En conjunto, la breve vida de Catalina marca un completo y modélico itinerario humano y cristiano: ante todo acoge el Evangelio como cristiana laica para después ascender a la mística y, desde tal monte Tabor de unión con el Amado, desciende, se encarna a fin de dar la vida por la Iglesia y la humanidad.

En efecto, en primer lugar, es laica y seglar, como todo nuevo cristiano y como la práctica totalidad de los cristianos. Alejada de sucedáneos y confusionismos laicistas o secularistas, desequilibrados y decadentes, sabe atraer el mundo a Dios, sin dejarse arrastrar por el mundo. La Encarnación misma entraña la secularización de Dios, su plena entrada en el "saeculum", en el orden temporal. En cuanto pueblo de Dios y rebaño del Pastor Jesús, la Iglesia entera es laica (de "laos", "pueblo" en griego), sin dejar de ser sacerdotal.

En segundo lugar, desde su cristianísima laicidad, Catalina asciende por caminos de ascética y oración a una íntima unión amorosa con Dios, a una mística unión. Madura así su pertenencia al Cuerpo Místico de Cristo, la Iglesia.

Por fin, el tercer y definitivo paso de una cristiana laica madura y profundamente unida a la eterna verdad del Amor viviente, es entrar de lleno en la vida pública para socorrer a todo tipo de necesitado en lo físico, lo intelectual, lo político y lo espiritual. Cual espejo del Santo Espíritu, refleja so- 
lícitamente los diversos dones del Señor y Dador de Vida. Entra en política con sabiduría humana y divina. Es mística, pero vive sin misticismos, con el corazón en el Cielo y los pies en la tierra. Sabedora de que en política se puede multiplicar la ayuda a millones de personas y a sociedades enteras, no rehúye afrontar las tensiones tectónicas entre los poderosos de este mundo.

Plena y maduramente laica, mística y divinamente enamorada, y encarnada en todas las heridas de los hombres de su tiempo, la eterna juventud de Catalina nos muestra con vigor la plenitud vital del cristiano. 